\title{
ОСОБЕННОСТИ ЛЕЧЕНИЯ ЧЕРЕПНО-МОЗГОВОЙ ТРАВМЫ ПРИ СОЧЕТАННОМ ПОВРЕЖДЕНИИ ПАРЕНХИМАТОЗНЫХ ОРГАНОВ У ДЕТЕЙ
}

\section{PECULIARITIES OF TREATMENT OF CRANIOCEREBRAL INJURY FOR COMBINED DAMAGE TO PARENCHYMAL ORGANS IN CHILDREN}

\section{Babich \\ A. Pshenichniy \\ M. Avanesov \\ Yu. Melnikov}

Summary. Every year there is an increase in children with concomitant trauma. Despite the rapid pace of development of medicine, there remains a high percentage of disability and deaths among victims, which makes the diagnosis and treatment of this pathology still a problem.

Keywords: hepatic rupture, splenic rupture, autolientransplantatsiya, splenectomy.

\section{Актуа^ьность}

каждым годом отмечается рост детей с сочетанной травмой.[1,2] Не смотря на стремительные темпы развития медицины, сохраняется высокий процент инвалидизации и летальных случаев среди пострадавших, что делает проблему диагностики и лечения сочетанной травмы актуальной.[3,4] В большинстве случаев причиной формирования сочетанной травмы является дорожно-транспортные происшествия, что достигает практически 90\%.[5,6] Сочетанная травма у детей во многих развитых странах является одной из главных причин летальности. Так, например, в США от полученных травм в год погибает около 6500 тысяч детей, в России - около 5500 тысяч. [7] Летальность при сочетанной нейротравме может достигать 25-30\%, при изолированной черепно-мозговой травме - значительно ниже
Бабич Игорь Иванович

Д.м.н, профессор, ФГБОУВО «Ростовский Государственный Медицинский Университет» Минздрава России babich-igor@yandex.ru

Пшеничный Александр Анатольевич Заведующий нейрохирургическим отделением, ГБУ РО «Областная детская клиническая больница» panaceya333@rambler.ru

Аванесов Михаил Сергеевич Врач-нейрохирург, ГБУРО «Областная детская клиническая больница» mihail-hx@yandex.ru

Мельников Юрий Николаевич

Аспирант, ФГБОУ ВО «Ростовский Государственный Медицинский Университет» Минздрава России pobzder@rambler.ru

Аннотация. С каждым годом отмечается рост детей с сочетанной травмой. Не смотря на стремительные темпы развития медицины, сохраняется высокий процент инвалидизации и летальных случаев среди пострадавших, что делает проблему диагностики и лечения данной патологии актуальной.

Ключевые слова: разрыв печени, разрыв селезенки, аутолиентрансплантация, спленэктомия, вдавленный перелом черепа.

и составляет 1-3\%. [8] Повреждения органов брюшной полости при сочетанной травме, согласно данным современной литературы, преобладают над повреждениями органов грудной клетки, и составляет около 30\%.[9] Следует отметить, что травмы паренхиматозных органов брюшной полости с массивным внутрибрюшным кровотечением всегда сопровождается значительным нарушением гемостаза и волемическим расстройствами. Включается механизм взаимного отягощения, увеличивается в динамике внутричерепные гематомы, повышается внутричерепное давление, что требует экстренной хирургической коррекции. Сочетанное повреждение селезенки и печени при этом составляет от $45 \%$ до $60 \%$. $[10,11]$

Одним из главных условий оказания медицинской помощи детям с сочетанной травмой является своев- 
ременная (укладываясь в понятие «золотого часа»), адекватная диагностика в условиях многопрофильной лечебной больнице. Тем не менее, из-за тяжести состояния пациента, транспортировка из лечебного учреждения оказания первичной врачебной помощи в специализированное многопрофильное лечебное учреждение не всегда рациональна. В связи с чем, первичным звеном оказания медицинской помощи являются ЦРБ и межрайонные центры, где оказание полноценной лечебно-диагностической помощи ребенку в условиях практического здравоохранения не всегда соответствует стандартам. Наиболее часто ургентными хирургами при повреждении селезенки выполняется спленэктомия, при вдавленных переломах костей черепа - хирургическая обработка, удаление костных отломков приводящее к формированию дефекта черепа.[12,13] В литературных источниках можно встретить множество научных статей, доказывающих развитие явлений аспленизма после проведения спленэктомии, высокий риск возникновения постспленэктомического сепсиса и пиемических осложнений. Удаление костных фрагментов во время экстренной обработки вдавленного перелома приводит к ряду нежелательных последствий, которые могут развиться у пациента в раннем и позднем послеоперационном периоде, а именно формирование синдрома «трепанированного» черепа, развитие эпилепсии и т.д. $[14,15,16]$

\section{Це^ь}

Улучшить результаты лечения пациентов с черепно-мозговой травмы при сочетанном повреждении паренхиматозных органов брюшной полости.

\section{Материал и методы}

Под нашим наблюдением с 2000 по 2020 год в клинике детской хирургии РостГМУ на базе ГБУ РО «ОДКБ» находилось 398 в возрасте от 1 месяца до 17 лет с сочетанным повреждением органов брюшной полости и черепно-мозговой травмой. В 78\% случаев (310 пациентов) доминирующим повреждением являлась абдоминальная травма с продолжающимся внутрибрюшным кровотечением.

В подавляющем большинстве сочетанная травма являлась следствием дорожно-транспортного происшествия - 246 пациентов (61,8\% случаев), бытовая -112 пациентов (28\% случаев), спортивная - у 40 пациентов (10,2\% случаев) больных.

По гендерному признаку пациенты поделились следующим образом: мальчики - 296 пациентов (74,4\% случаев), девочки - 102 пациента (25,6\% случаев).
По возрастной градации: от 0-3 лет- 32 пациента (8\% случаев), от 3-7лет - 56 пациентов (14,1\% случаев), от 8-12 лет -83 пациента (20,9\% случаев), 13-15 лет- 129 пациентов (32,4\% случаев), старше $15 л е т-98$ пациентов (24,6\% случаев).

Повреждение поджелудочной железы наблюдалось у 106 пациентов (26, 6\% случаев). По характеру повреждения поджелудочной железы: у 32 пациентов (30,2\% случаев) ушиб железы с образованием ненапряженной подкапсульной гематомы, у 43 пациентов (40,5\% случаев) ранение, разрыв или размозжение железы без повреждения главного панкреатического протока, у 28 пациентов (26,4\% случаев) ранение, разрыв или размозжение железы с повреждением главного панкреатического протока, у 3 пациентов (2,9\% случаев) сочетанное панкреатодуоденальное повреждение.

Повреждение селезенки наблюдалось у 293 пациентов (73, 6\% случаев). По характеру повреждения селезенки: у 58 пациентов (19,8\% случаев) отграниченные разрывы (трещины) капсулы или подкапсульная гематома, без значительных повреждений паренхимы, у 90 пациентов (30,7\% случаев) единичные или множественные разрывы капсулы или паренхимы, поперечные или продольные, не распространяющиеся к воротам, интрапаренхиматозная гематома, у 76 пациентов (26\% случаев) глубокие разрывы, единичные или множественные, поперечные или продольные, распространяющиеся к воротам и вовлекающие сегментарные сосуды, у 69 пациентов (23,5\% случаев) размозжение селезенки, ее фрагментация или отрыв от сосудов в воротах.

Повреждение печени отмечалось у 136 пациентов (43,8\% случаев). По характеру повреждения печени: у 39 пациентов (28,7\% случаев) повреждение печени без разрыва капсулы, у 87 пациентов (64\% случаев) разрыв печени с повреждением капсулы, у 10 пациентов (7,3\% случаев) центральный разрыв печени.

Черепно-мозговая травма наблюдалась у всех пациентов (100\% случаев). По анатомической локализации повреждения костей свода черепа распределилась следующим образом: теменная кость - 159 пациентов (40\% случаев), лобная кость - у 107 пациентов (27\% случаев), височная -у 107 пациентов (27\%случаев), затылочная у 25 пациентов (6\% случаев). По характеру повреждения: закрытые (без повреждений кожных покровов) встречались у 68 пациентов (17\% случаев), открытые не проникающие за пределы твердой мозговой оболочки -у 239 пациентов (60\% случаев), открытые проникающие травмы с повреждением ТМО у 91 пациента (23\% случаев). По размерам костного дефекта: у 67 пациентов (17\% случаев) малые (до $\left.10 \mathrm{~cm}^{2}\right)$, у 251 пациентов (63\% случаев) 


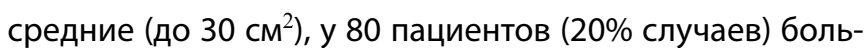
шие (до $60 \mathrm{~cm}^{2}$ ).

Основными причинами интракраниальной компрессии по данным РКТ головного мозга явились: у 199 пациентов (50\% случаев) пластинчатая эпи- и субдуральные гематомы, у 107 пациентов (27\% случаев) очаги ушиба I типа, у 92 пациентов (23\% случаев) II типа.

Bсе 310 пациентов с доминирующей абдоминальной травмой были разделены нами на 2 группы. В основную группу вошло 140 пациентов (45\% случаев) первоначально поступивших и прооперированных в ГБУ РО «ОДКБ». Группа сравнения состояла из 170 пациентов (55\% случаев). Данная группа пациентов была прооперирована в ЦРБ и межрайонных центрах и для дальнейшего лечения по линии санитарной авиации доставлена в ГБУ РО «ОДКБ». В связи с характером повреждений и тяжестью состояния лечение пациентов обеих групп осуществлялось, как правило, в два этапа. Первый этап заключался в остановке продолжающегося внутрибрюшного кровотечения, стабилизации состояния пациента, корректировки гемостаза, восстановления волемических нарушений. Вторым этапом выполнялась хирургическая коррекция черепно-мозговой травмы.

Описательная статистика количественных признаков представлена в виде центральной тенденции медианы (Ме) и интерквартильного размаха [25 и 75 процентили], среднего значения (М), стандартного отклонения среднего значения (б) и процентного соотношения для качественных показателей. В тексте представлено как Me [LQ; UQ] (min-max), M \pm б. Проверка на нормальность распределения проводилась с использованием критериев Шапиро-Уилка, Колмагорова-Смирнова. С целью статистического анализа для количественных показателей использовались параметрический критерий Стьюдента и непараметрический критерий Манна-Уитни, оценка качественных показателей выполнялась с использованием критерия Пирсона (хи-квадрат) и точного теста Фишера. Статистическую обработку результатов осуществляли с помощью пакета прикладных программ Statistica 10.0 («StatSoft», США) и Microsoft Office Excel 2020 («Microsoft», США). Для всех сравниваемых величин достигнутый уровень значимости (р) считался статистически достоверным при $р<0,05$.

\section{Результаты и обсужление}

Все дети имеющие повреждение головного мозга и паренхиматозных органов поступали в больницу в тяжелом состоянии, с признаками травматического и геморрагического шока. Повреждение паренхиматозных органов с обильным внутрибрюшным кровотечением усугубляло тяжесть течения черепно-мозговой травмы.
На фоне гемодинамических нарушений формировались ишемически- гипоксические изменения головного мозга, и как следствие нарастание отека головного мозга с высоким риском развития дислокационного синдрома и вклинения. В связи с этим, первым этапом проводилась хирургическая остановка внутрибрюшного кровотечения, а вторым этапом оперативная коррекция черепно-мозговой травмы. Стоит отметить, что нейрохирургическое пособие выполнялось всем больным не позже чем через 24-48 часов с момента получения травмы. Всем пациентам основной группы и группы сравнения временно интраоперационно устанавливался эпидуральный датчик внутричерепного давления (использовались датчики «Spiegelberg»).

У 74 пациентов (53\% случаев) основной группы при комбинированном повреждении печени и селезенки, в случае невозможности выполнения радикального гемостаза, проводилась спленэктомия с аутотрансплантацией селезеночной ткани в рану печени с целью остановки кровотечения и профилактики синдрома постспленэктомической иммунодепрессии. (патент РФ № 2305502). У 64 пациентов (46\% случаев) при значительной травме селезенки с продолжающимся кровотечением в сочетании с повреждением хвоста поджелудочной железы выполнялась спленэктомия с эндоскопической аутотрансплантацией гомогената селезеночной ткани под капсулу печени. (патент РФ № 2610361). У 45 пациентов (32\% случаев) при фрагментации хвоста поджелудочной железы в сочетании с центральным разрывом селезенки, а также при поперечных разрывах непосредственно головки и тела поджелудочной железы применялась следующая хирургическая тактика: полностью удалялись все фрагменты, останавливалось кровотечение, культя ПЖ герметизировалась Z -образным вворачивающимся швом с последующей герметизацией линии шва клеем «Evicel». После купирования кровотечения и получения данных СКТ, больным оценивали характер черепно-мозговой травмы. Всем пациентам основной группы при наличии вдавленного перелома костей черепа с углублением костных фрагментов более чем на 10 мм, повышения внутричерепного давления выполнялась хирургическая коррекция, заключающаяся в краниотомии и одномоментном закрытии костного дефекта по разработанной нами методике. (патент РФ№ 2683067).

В группе сравнения 124 пациентам (73\% случаев) при повреждениях селезенки с массивным внутрибрюшным кровотечением в сочетании с повреждением паренхимы печени выполнялась спленэктомия. У 88 пациентов (52\% случаев) при фрагментации хвоста поджелудочной железы выполнялась контрикал - новокаиновая блокада, останавливалось кровотечение из сосудов гематомы, полость малого сальника дре- 
нировалась через левую поясничную область силиконовой трубкой с внутренним диаметром 4-5 мм. У 39 пациентов (23\% случаев) при линейных разрывах тела поджелудочной железы осуществлялось ушивание капсулы и дренирование полости малого сальника. Вторым этапом всем пациентам группы сравнения выполнялась коррекция черепно-мозговой травмы, заключающаяся в хирургической обработке вдавленного перелома с удалением костных отломков и формированием костного дефекта, резекционно-декомпрессивной краниотомии. После стабилизации состояния данные пациенты отправлялись в ГБУ РО «ОДКБ», где им осуществлялась краниопластика артифициальной титановой сетчатой пластиной.

У всех пациентов группы сравнения после спленэктомии в раннем послеоперационном периоде наблюдались стойкие подъемы температуры до фебрильных цифр, по данным исследования анализа крови отмечалось длительное повышение показателей СРБ (до 55мг/л), лейкоцитоза (до 22×10*9/л), повышение показатели СОЭ (до 20 мм/ч) в течение 6-7 дней, что требовало пролонгировать проведение массивной антибактериальной терапии. Таких детей катамнестически наблюдали в течение 1 года, и было выявлено, что у пострадавших со спленэктомией прослеживалось снижение показателей Т-клеточного иммунитета и увеличение активации В-лимфоцитов, что свидетельствует о выраженном нарушении взаимодействий Т- и В-лимфоцитов. Пациенты были расположены к развитию ОРВИ (5-7 раз в год), воспалительных изменений кожи, обострение хронических заболеваний.

Пациенты основной группы, которым выполнялась органосберегающая операции, по разработанной методике, в раннем послеоперационном периоде инфекционных осложнений не наблюдалось, показатели крови стабилизировались к 3-му дню с момента проводимой хирургической коррекции. В отдаленном периоде изменений в иммунограмме не выявлено, склонности к явлению аспленизма не было.

В группе сравнения у 52 пациентов (60\% случаев) с повреждением поджелудочной железы наблюдалось образование свищей с обильным панкреатическим отделяемым, которые нуждались в дополнительной хирургической коррекции. У 13 пациентов (15\% случаев) отмечалось образование ложных кисти, также с последующим оперативным лечением. Данные пациенты требовали неоднократного госпитального лечения.

В основной группе панкреатический свищ наблюдался у 1 пациента (0,7\% случаев), который самостоятельно закрылся через 2 месяца, ложных кист при этом не выявлено.
У 39 пациентов (23\% случаев) группы сравнения после резекционно-декомпрессивной краниотомии с костным дефектом, в раннем и позднем послеоперационном периодах наблюдалось развитие синдрома «трепанированного» черепа, формирование эпиактивности (по данным ЭЭГ, клинически - развитие структурной посттравматической эпилепсии). У пациентов группы сравнения с черепно-мозговой травмой перенесших спленэктомию в раннем послеоперационном периоде наблюдались осложнения в виде: воспаления в зоне титановой пластины (что требовало ее удаления) у 8 пациентов (6,5\% случаев), формирования пролежня кожных покровов над титановой пластиной (выполнялась кожная пластика) у 7 пациентов (6,4\% случаев), воспалительных изменений в области послеоперационной раны (выполнена ревизия, иссечение краев поврежденной ткани) у 12 пациентов (9,7\% случаев).

У пациентов основной группы, которым проводилась обработка вдавленного перелома черепа по разработанной нами методике данные симптомы и синдромы не наблюдались, пиемических осложнений не выявлено.

В основной группе длительность пребывания пациентов в отделении реанимации составила Ме-8, [6;10], (5-13), М \pm б-7,8 0,3 , количество койко-дней проведенный в хирургическом стационаре Ме-15, [13;17], (10-23), $M \pm \sigma-14,6 \pm 0,5$. В контрольной группе длительность пребывания пациентов в отделении реанимации составила Ме-14, [12;17], (9-19), М $\pm \sigma-13,2 \pm 0,4$, количество койко-дней проведенный в хирургическом стационаре Me-23, [18;26], (12-28), $M \pm \sigma-22,8 \pm 0,4$.

\section{Выво $\Delta ы$}

1. При повреждении паренхиматозных органов брюшной полости в сочетании с черепно-мозговой травмой наблюдается выраженный синдром взаимного отягощения, проявляющийся в существенном нарушении гемостаза и требующий дополнительной коррекции.

2. При повреждении печени и селезенки с выраженным гемоперитонеумом и черепно-мозговой травмой необходима установка датчика ВчД и отсроченная коррекция вдавленного перелома черепа после адекватной коррекции гемостаза.

3. При вдавленных переломах костей черепа одномоментная пластика дефекта по разработанной методике является методом выбора и позволяет сократить развитие осложнений в послеоперационном периоде.

4. При массивных травмах селезенки необходимо выполнять аутотрансплантацию селезеночной ткани, позволяющей предотвратить развитие осложнений после коррекции вдавленного перелома черепа. 


\section{ЛИТЕРАТУРА}

1. Артарян А.А., Иова А.С., Гармашов Ю.А., Банин А.В. Черепно-мозговая травма у детей // Черепно-мозговая травма. Клиническое руководство (под ред. А.Н. Коновалова, Л.Б. Лихтермана, А.А. Потапова), М.- Т2, 2000 г. -2 .

2. Бабич И.И., Мельников Ю.Н., Пшеничный А.А., Аванесов М.С. Диагностика и новый метод лечения вдавленных переломов черепа у детей // Современная наука: актуальные проблемы теории и практики. Серия: Естественные и технические науки. № 7; 2020; с. 178-181. D0I 10.37882/2223-2966.2020.07.01

3. Бабич И.И., Пшеничный А.А., Аванесов М.С., Мельников Ю.Н. Сравнительный анализ результатов хирургического лечения приобретенной деформации черепа с использованием аутопластики и краниопластики титановой пластиной // Современные проблемы науки и образования. — 2021. — № 1; URL: http://www.science-education.ru/article/view?id=30528 (дата обращения: 20.02.2021). D0I 10.17513/spno.30528

4. Кравчук А.Д., Потапов А.А., Лихтерман Л.Б., Еропкин С.В. Посттравматические повреждения черепа. Клиническое руководство по черепно-мозговой травме. Под редакцией Коновалова А.Н., Лихтермана Н.Б., Потапова А.А. «Антидор», М., 2002, 3, 147-165

5. Лебедев Э.Д. Основные дефекты организации медицинской помощи больным с острой черепно-мозговой травмой в крупном городе // Бюл. Укр. ассоциации нейрохирургов. - 1998. - № 5.- С. 71.

6. Подкаменев В.В., Пикало И.А., Зайцев А.П. Сочетанная летальная травма у детей: риск смерти от повреждений селезенки. Хирургия. Журнал им. Н.И. Пирогова. 2013;(3):61-65.

7. Подкаменев В.В., Пикало И.А., Зайцев А.П. Сочетанная летальная травма у детей: риск смерти от повреждений селезенки. Хирургия. Журнал им. Н.И. Пирогова. 2013;(3):61-65.

8. Подкаменев В.В, Пикало И.А, Зайцев А.П. Повреждение селезенки при сочетанной летальной травме у детей // Гематология и трансфузиология: 2012.N6., C 12-14.

9. Подкаменев В.В., Пикало И.А., Зайцев А.П. Сочетанная летальная травма у детей: риск смерти от повреждений селезенки. Хирургия. Журнал им. Н.И. Пирогова. 2013;(3):61-65.

10. Суворов С.Г., Езельская Л.В., Розинов В.М., и др. Организация специализированной медицинской помощи детям, пострадавшим в дорожно-транспортных происшествиях на территории Московской области // Анестезиология и реаниматология.— 2009.— № 1.— С. 34-37.

11. Суворов С.Г., Езельская Л.В., Розинов В.М., и др. Организация специализированной медицинской помощи детям, пострадавшим в дорожно-транспортных происшествиях на территории Московской области // Анестезиология и реаниматология.— 2009._ № 1.— С. 34-37.

12. Шаршов Ф.Г., Спиридонова Е.А., Румянцев С.А., и др. Формализация медицинской документации и стандартизация действий при оказании экстренной помощи детям с тяжелой травмой на этапе межгоспитальной транспортировки // Скорая медицинская помощь. — 2011.— Т. 12.—№ 2.—C. 26-30.

13. Шаршов Ф.Г., Спиридонова Е.А., Румянцев С.А., и др. Формализация медицинской документации и стандартизация действий при оказании экстренной помощи детям с тяжелой травмой на этапе межгоспитальной транспортировки // Скорая медицинская помощь. — 2011.— Т. 12.— № 2.—C. 26-30.

14. Araki T., Yokota H., Morita A., Pediatric traumatic brain injury: characteristic features, diagnosis, and management, Jpn. Neurosurg. Soc. 57 (2) (2017) 82-93, https:// doi.org/10.2176/nmc.ra.2016-0191.

15. Bhandari M, Guyatt G.H., Khera V. Operative management of lower extremity fractures in patients with head injuries // Clin. Orthop. Relat. Res. - 2013.— Vol. 407.- P. 187-198

16. Management of Pediatric Trauma. Buntain W.L., ed. Philadelphia:WB Saunders, 1995: 788

( ) Бабич Игорь Иванович ( babich-igor@yandex.ru ), Пшеничный Александр Анатольевич ( panaceya333@rambler.ru ), Аванесов Михаил Сергеевич ( mihail-hx@yandex.ru ), Мельников Юрий Николаевич ( pobzder@rambler.ru ).

Журнал «Современная наука: актуальные проблемы теории и практики» 